\title{
La Confederación Anticomunista Latinoamericana. Las conexiones civiles y militares entre Guatemala y Argentina \\ (1972-1980)
}

Julieta CARLa Rostica*

Artículo recibido: 16 de octubre de 2016

Artículo aprobado: 18 de marzo de 2017

Doi: http://dx.doi.org/10.12804/revistas.urosario.edu.co/desafios/a.5227

Para citar este artículo: Rostica, J. (2018). La Confederación Anticomunista Latinoamericana. Las conexiones civiles y militares entre Guatemala y Argentina (1972-1980). Desafíos, 30(1), 309-347. Doi: http://dx.doi.org/10.12804/revistas.urosario.edu.co/desafios/a.5227

\section{Resumen}

El ejercicio de la represión politica en las zonas urbanas en Argentina y Guatemala desde mediados de los años setenta hasta mediados de los años ochenta, especificamente la desaparición forzada de personas, presenta varias similitudes. Nuestra bipótesis es que dichas similitudes se explican por la colaboración argentina en la lucha contrasubversiva en Guatemala a los órganos vertebrales que producen la desaparición forzada, como la inteligencia civily militar. A nuestro juicio, la transferencia de recursos, conocimientos y experiencias de Argentina bacia Guatemala se

\footnotetext{
* Socióloga de la Universidad de Buenos Aires (UBA), magíster en estudios latinoamericanos (UAM) y doctora mención Ciencias Sociales y Humanas (UNQUI). Es investigadora adjunta del Consejo Nacional de Investigaciones Científicas y Técnicas y docente de Historia Social Latinoamericana en la carrera de Sociología así como en la Maestría en Estudios Sociales Latinoamericanos de la Facultad de Ciencias Sociales, Universidad de Buenos Aires. Correo electrónico: julietarostica@yahoo.com orCID: http://orcid.org/0000-0002-2107-2797
} 
realizó no solamente a través de canales diplomáticos y oficiales, sino también a través de las conexiones civiles y militares (secretas, informales y clandestinas) como la red transnacional de extrema derecha denominada Confederación Anticomunista Latinoamericana (CAL). En este articulo nos propusimos mostrar una de las condiciones de posibilidad para esa transferencia de recursos: la participación de la extrema derecha guatemalteca en la red latinoamericana de la CAL y sus conexiones con Argentina. Para ello utilizamos sobre todo documentos desclasificados del Archivo Histórico de la Cancillería Argentina y del Centro de Documentación y Archivo para la Defensa de los Derechos Humanos de Paraguay.

Palabras clave: sociología histórica, dictadura, violación de los derechos humanos, conservatismo, Guatemala, Argentina.

\title{
The Latin American Anticommunist Federation. Civil and Military Connections between Guatemala and Argentina (1972-1980)
}

\begin{abstract}
The exercise of political repression in urban areas in Argentina and Guatemala from the mid-1970s to the mid-1980s, specifically the forced disappearance of people, has several similarities. My argument is that these similarities are explained by the Argentinean collaboration in the countersubversive struggle in Guatemala, in particular with state entities that produced forced disappearance, such as civilian and military intelligence. The transfer of resources, knowledge and experiences from Argentina to Guatemala was carried out not only through diplomatic and official channels, but also through civil and military, secret, informal and clandestine connections, such as the right-wing transnational network called Confederación Anticomunista Latinoamericana (CAL). I illustrate one of the conditions for making this resource transfer possible: the participation of the extreme right in Guatemala within the CAL and its connections with Argentina. In doing so I use declassified documents from the Historical Archive of the Argentinean Ministry of Foreign Affairs and the Center for Documentation and the Archive for the Defense of Human Rights of Paraguay.
\end{abstract} Keywords: Historical sociology, dictatorship, human rights violations, conservatism, Guatemala, Argentina 


\section{A Confederação Anticomunista Latino- americana. As conexões civis e militares entre a Guatemala e a Argentina (1972-1980)}

\section{Resumo}

O exercício da repressão política nas zonas urbanas na Argentina e na Guatemala desde mediados dos anos setenta até mediados dos anos oitenta, especificamente a desaparição forçada de pessoas, apresenta várias similitudes. A nossa bipótese é que ditas similitudes explicam-se pela colaboração argentina na luta contra-subversiva na Guatemala, nos órgãos vertebrais que produzem a desaparição forçada, como a inteligência civil e militar. Ao nosso juį́o, a transferência de recursos, conhecimentos e experiências da Argentina à Guatemala realizou-se não só através de canais diplomáticos e oficiais, mas também através das conexões civis e militares, secretas, informais e clandestinas, como foi a rede transnacional de extrema direita denominada Confederação Anticomunista Latino-Americana (CAL). Neste artigo propusemonos mostras uma das condições de possibilidade para essa transferência de recursos: a participação da extrema direita guatemalteca na rede latino-americana da CAL $e$ as suas conexões com a Argentina e para isso utilizamos, especialmente, documentos desclassificados do Arquivo Histórico da Chancelaria Argentina e do Centro de Documentação e Arquivo para a Defesa dos Direitos Humanos do Paraguai.

Palavras-chave: sociologia histórica, ditadura, violação dos direitos humanos, conservadorismo, Guatemala, Argentina.

\section{Introducción}

Después del golpe de Estado de 1954 en Guatemala —el desembarco de la Guerra Fría en América Latina mediante la primera operación encubierta exitosa de la CIA-, se inició un largo proceso sociohistórico de violencia política que culminó en la desaparición forzada y muerte de más de 200 mil personas, hacia fines de los años setenta y principios de los ochenta. La violencia represiva implementada por el Estado guatemalteco en las áreas urbanas contrastó con la llevada a cabo en las zonas rurales e indígenas, donde las masacres indiscriminadas, las campañas de tierra arrasada y los actos de genocidio fueron sistemáticos. En las zonas urbanas, según los informes de 
la Comisión Interamericana de Derechos Humanos de 1981, 1983 y 1985, la Comisión para el Esclarecimiento Histórico (CEH, 1999) y algunas sentencias de la Corte Interamericana de Derechos Humanos (Caso Gudiel, 20/11/2012; Caso García y otros 29/11/2012; Caso Bámaca Velásquez, 25/11/2000), la desaparición forzada de personas se convirtió en uso frecuente de los grupos paramilitares durante la década del setenta. A partir del gobierno de Romeo Lucas García (1978-1982), la detención ilegal y la desaparición forzada se convirtieron en una modalidad represiva de las instituciones militares y los grupos paramilitares en todo el territorio nacional. Luego del golpe de Estado de 1982, esta modalidad represiva mermó debido al desmantelamiento de los grupos paramilitares, pero presentó un incremento descomunal durante el gobierno del general Óscar Humberto Mejía Víctores (1983-1985), la segunda etapa de la dictadura, bajo la responsabilidad de las fuerzas de seguridad del Estado (CIDH, 1985; CEH, 1999, p. 459). La desaparición forzada de personas en Guatemala se practicó de forma sistemática y masiva, pero en la Ciudad de Guatemala esta tuvo "elementos característicos coincidentes" que permiten distinguir diferentes etapas y un modus operandi típico (detención-interrogatorio-desaparición) ${ }^{1}$. Si bien recién se está investigando el funcionamiento más minucioso de la inteligencia militar en los casos de desaparición forzada de personas, como en la causa Molina Theissen o Diario Militar, podemos adelantar que el Manual de guerra contrasubversiva recuperaba los principios de dirección centralizada y ejecución descentralizada. Establecía los dos factores esenciales de la organización de la inteligencia en la lucha contra la subversión: "la multiplicación de las agencias de búsquedas, por un lado, y la unidad de la explotación, por otro". En otro párrafo expresaba la

\footnotetext{
1 La CEH trabajó sobre una muestra de 6159 casos de desaparición forzada y Carlos Figueroa Ibarra (1999) sobre una muestra 4042. De acuerdo al historiador Arturo Taracena Arriola (2007, p. 103) hubo un desbalance en las sedes que ubicó la CEH: fueron numéricamente mayores en las regiones indígenas que en las regiones ladinas (de población mestiza) lo que provocó un desequilibrio entre la investigación de la violencia en el ámbito urbano y el rural y, por ende, en la recopilación de los datos. En nuestra entrevista a Ana González, la experta argentina que estuvo a cargo de dichas regiones ladinas en la investigación de la CEH, esgrimió lo mismo que el historiador. Esto nos mueve entonces a considerar los datos ofrecidos por Carlos Figueroa Ibarra.
} 
necesidad de la conciliación de "las exigencias de la centralización en el procesamiento, utilización y orientación y de la descentralización en la búsqueda"2 (Ejército de Guatemala, s.f., p. 215). La Dirección de Inteligencia del Estado Mayor de la Defensa Nacional conocía la totalidad de la información, lo cual funcionaba paralelamente a una compartimentación o subdivisión de las zonas militares, donde las operaciones ilegales de inteligencia se planearon y desarrollaron de forma clandestina. Así, en Guatemala, se utilizaron las que se denominaron popularmente "cárceles clandestinas". La Dirección de Inteligencia funcionó a la par de otra oficina de inteligencia del Estado Mayor Presidencial conocida como La Regional o El Archivo (CEH, 1999, pp. 74-147. Estos elementos característicos presentan rasgos muy similares a la forma en que la desaparición forzada se ejecutó en Argentina durante la dictadura cívico-militar (1976-1983).

En Argentina, la desaparición forzada de personas fue una práctica citadina. El modus operandi fue muy parecido y respondió al ciclo reiterado de detención ilegal, interrogatorio y desaparición, tal como documentan un informe de la CIDH (1980), el Informe de la Comisión Nacional sobre la Desaparición de Personas (CONADEP, 1984) y algunas sentencias judiciales revisadas con detenimiento (Causa 1914, 12/03/2009; Causa 1960, 27/12/2012; Causa 17,13/11/2015). En este ciclo, los centros clandestinos de detención (CCD) tuvieron un rol central. El prisionero solía ser recibido en el CCD por el personal del destacamento de inteligencia de la subzona, personal que manejaba la información existente y de acuerdo con ella orientaba el "interrogatorio" (tortura). De este modo, la ejecución de las operaciones fue descentralizada. La aplicación de tormentos tenía una función principal: la obtención de información operativamente útil que permitiera la captura de otra persona, de armas, de una casa de seguridad, una base operativa, etcétera. El proceso de desaparición concluía con la

2 Utilizo el Manual de guerra contrasubversiva entregado a fines de enero de 2006 por el ministro de la Defensa Nacional de Guatemala a la Unidad de Casos Especiales y Violaciones a los Derechos Humanos del Ministerio Público. El general entregó en esta fecha la copia 001947. Se estima, por diversas motivos que no vienen al caso desarrollar, que era usado por el ejército hacia fines de los años setenta. 
dimensión negacionista del final, la desaparición del cuerpo y con él del crimen (Calveiro, 2006, pp. 60-61). La prioridad era que el circuito no se cortara para que el llamado "mosaico" o la "cadena de personas" se prolongara hasta llegar a las supuestas cúpulas de la "subversión" de las organizaciones político-administrativas locales (OPA) o a dirigentes sociales y políticos. La información obtenida luego se remitía a la Central de Reunión de Información del Batallón de Inteligencia 601, el organismo que centralizaba las declaraciones. De este modo, se centralizó la información y se unificó el mando de la producción de inteligencia. La inteligencia militar fue vertebral y le daba sentido a todo el circuito: al secuestro, al centro clandestino de detención, al interrogatorio, a la delación y a la desaparición forzada. Según el manual argentino Operaciones contra elementos subversivos, recuperado en el manual guatemalteco anteriormente citado, la inteligencia constituía la base fundamental en que se apoyaba la lucha contra la subversión (Ejército Argentino, 1977, pp. 141-142). Tanto en Argentina como en Guatemala, los responsables fueron las Fuerzas Armadas y las Fuerzas de Seguridad, y solo en un comienzo parapoliciales y paramilitares que respondían a ellas. La columna vertebral: la Jefatura II de Inteligencia del Estado Mayor General del Ejército, la G-2.

Estas similitudes entre Guatemala y Argentina se encuadran históricamente en el desarrollo de la Guerra Fría en América Latina y el consenso sobre la doctrina de seguridad nacional, la cual se alimentó, especialmente en nuestros casos, de la teoría de la Guerra Revolucionaria y de las técnicas de contrainsurgencia provenientes de la escuela militar francesa. Las similitudes se complementan con otras que han resultado de las comparaciones que hemos hecho en investigaciones anteriores entre algunas dimensiones de las dictaduras institucionales de las Fuerzas Armadas (la dictadura cívico-militar argentina de 1976-1983 y la dictadura guatemalteca de 1982-1985), como la ideología y la forma de organización política (Rostica, 2015). No obstante, la metodología comparativa utilizada desde la perspectiva de la sociología histórica no culmina en encontrar patrones comunes o contrastantes. A través de la comparación analítica se confrontan dos unidades equivalentes para identificar variables independientes que sirvan para explicar dichas similitudes y diferencias. Desde el 
posicionamiento disciplinario de la sociología histórica, por ende, es fundamental imaginar hipótesis explicativas a las similitudes de las desapariciones forzadas, para lo cual indagamos sobre una variable que hasta el momento no había sido investigada profundamente: la posible colaboración argentina en la lucha contrasubversiva en Guatemala. Más concretamente, la colaboración argentina en los órganos vertebrales que producen la desaparición forzada, como la inteligencia civil y militar. Nuestra hipótesis de trabajo es que las similitudes en el ejercicio de la represión en las zonas urbanas en Argentina y Guatemala, específicamente el mecanismo de la desaparición forzada de aquellos considerados subversivos, se explica por la transferencia de recursos, conocimientos y experiencias en inteligencia desde Argentina hacia Guatemala y su aplicación práctica ${ }^{3}$.

Creemos que esa transferencia de conocimientos se materializó a través de canales diplomáticos formales e informales, públicos y reservados, así como también clandestinos. Ya hemos indagado en las relaciones exteriores que se mantuvieron entre ambos países y en la cooperación en materia de seguridad nacional. Hemos podido documentar la formación en inteligencia de oficiales guatemaltecos de alto rango en Argentina, los asesores argentinos que fueron en comisión hacia América Central y la recepción de la producción militar argentina en el Manual de guerra contrasubversiva de Guatemala (Rostica, 2013; 2015; 2016). Sin embargo, creemos que falta indagar con mayor profundidad la posible transferencia de recursos de Argentina hacia Guatemala a través de las conexiones civiles y militares — secretas, informales y clandestinas - como la red transnacional de extrema derecha denominada Confederación Anticomunista Latinoamericana (CAL). En este artículo mostraremos con fuentes documentales la participación de la extrema derecha guatemalteca en la red latinoamericana de la CAL y sus conexiones con Argentina, una vía posible para ingresar a un problema de enorme complejidad para la investigación

\footnotetext{
3 Este artículo forma parte de los resultados de una investigación más grande que dirijo PICT 2013-0751, La colaboración argentina y sus consecuencias en la lucha antisubversiva en Guatemala y El Salvador (1962-1983), Fondo para la Investigación Científica y Tecnológica, Agencia Nacional de Promoción Científica y Tecnológica, Argentina.
} 
académica, ya sea por la desaparición de documentos como por los juicios abiertos en la actualidad. El periodo elegido va desde 1972, año en que nace la CAL, hasta 1980, un año marcado por intensas relaciones diplomáticas entre Argentina y Guatemala y por la realización del IV Congreso de la CAL en Argentina. Dicho congreso se había enfocado en América Central tras el triunfo de James Carter en Estados Unidos y su política de restricción a los países cuyos regímenes autoritarios violaban los derechos humanos, el triunfo de la revolución nicaragüense, el asilo de Somoza en Paraguay y el asesinato de Adolfo Cuéllar en El Salvador, fundador de la CAL y director de ORDEN. Cabe agregar que no hemos encontrado documentos sobre posibles congresos de la CAL posteriores a 1980, con lo cual, hasta el momento, el realizado en Buenos Aires es el último congreso del cual se tiene registro.

El artículo desarrolla, primero, un estado de la cuestión que pone la originalidad del tema en el marco de los estudios sobre la Guerra Fría en América Latina. Posteriormente, describe sucintamente el desarrollo del anticomunismo en Guatemala desde el proceso revolucionario (1944-1954) en adelante, con un énfasis especial en los pactos entre civiles y militares en la lucha contra la subversión. Finalmente, muestra las conexiones entre civiles y militares y entre guatemaltecos y argentinos de y a través de la CAL.

\section{Estado actual de conocimiento sobre el tema}

Hay varias referencias bibliográficas, sobre todo periodísticas, que señalan la asistencia de la dictadura cívico-militar argentina en Centroamérica en materia contrasubversiva (Duhalde, 1983; Dabat \& Lorenzano, 1984; Cardoso, Kirschbaum \& van Der Kooy, 1983). No obstante, son muy pocas las menciones específicas sobre la colaboración a Guatemala. Varias de sus afirmaciones, hechas a principios de los años ochenta, se respaldaban en la sesión sobre Guatemala del Tribunal Permanente de los Pueblos, realizada en Madrid del 27 al 31 de enero de 1983 y específicamente en el testimonio de Elías Barahona, un infiltrado del Ejército Guerrillero de los Pobres en el 
Ministerio del Interior durante el gobierno del general Romeo Lucas García. A comienzos de septiembre de 1980, desde Panamá, declaró que los gobiernos de Israel, Chile y Argentina proporcionaban la mayor parte de la ayuda y asesoría militar que el gobierno demandaba y que había unos doscientos oficiales guatemaltecos cursando estudios en las academias argentinas, especializándose en técnicas de interrogatorio y tácticas de represión, datos que ratificó ante el Tribunal Permanente de los Pueblos de $1983^{4}$. Entre los estudios sobre las relaciones internacionales de Argentina destacan el trabajo de Russell y Tokatlian (1986) y el de Cisneros y Escudé (2000), quienes diferencian la política exterior de la dictadura para cada uno de los países de la región centroamericana y afirman que, para el caso de Guatemala, se combinó el mantenimiento del statu quo y la defensa del principio de no intervención con el envío de armas y el asesoramiento en técnicas de lucha antisubversiva.

En el marco de los estudios históricos sobre la Guerra Fría, el trabajo más conocido es el de Ariel Armony, quien afirmó que los perpetradores de la "guerra sucia" en Argentina trasladaron a fines de los años setenta y comienzos de los ochenta su modelo de represión masiva a América Central. Su investigación tuvo por objetivo mostrar que Argentina decidió “ocupar el lugar de los Estados Unidos en la lucha hemisférica contra el comunismo" cuando la subversión ya no se percibió como una amenaza seria en el ámbito interno. Argentina, que "en un principio operó como un actor independiente en América Central, [se erigió luego] en un sucedáneo calificado en el programa de política exterior del gobierno de Reagan para esa región" (Armony, 1999, p. 69). En este libro, Armony (1999) detalló la asistencia militar que Argentina presuntamente ofreció a Guatemala, El Salvador, Honduras y Nicaragua.

\footnotetext{
4 Testimonio de Elías Barahona, Centroamérica, mayo de 1982, Centro Académico de la Memoria de Nuestra América (CAMeNA), Universidad Autónoma de la Ciudad de México, caja 141, expediente T-GT3 y caja 9, expediente B-GT8, serie Guatemala, sección régimen político y gobierno.
} 
El tratamiento que realizó Ariel Armony para cada uno de los países de la región centroamericana no es el mismo. Las referencias sobre Guatemala son muy sucintas y escasas. En el apartado específico que le dedicó señaló que, precisamente cuando el gobierno de Carter canceló la asistencia militar a Guatemala, Argentina pasó a ocupar su lugar. Incrementó las ventas de material militar, se convirtió en uno de los principales proveedores de instrucción en técnicas de inteligencia avanzada para las unidades de la élite del ejército y participó activamente en los escuadrones de la muerte. Según su pesquisa, la ayuda militar a Guatemala data de 1977 y de un convenio secreto firmado entre 1982 y 1983; la instrucción en técnicas de inteligencia avanzadas de la fuerzas de élite guatemalteca G-2 de principios de 1980; el entrenamiento avanzado en inteligencia, incluido el uso de "técnicas de interrogatorio" de doscientos oficiales guatemaltecos en Campo de Mayo tras un convenio secreto firmado entre autoridades militares en octubre de 1981. También mencionó que el personal militar argentino trabajó con el Ejército Secreto Anticomunista, una de las organizaciones paramilitares guatemaltecas de mayor actividad hacia comienzos de los años ochenta (Armony, 1999, pp. 146-147). Muchas de estas afirmaciones son citas de la bibliografía periodística que hemos mencionado antes, están basadas en fuentes hemerográficas y algunas no están documentadas. Los documentos oficiales argentinos desclasificados en la última década, como los Boletines Reservados del Ejército o la enorme cantidad de documentos secretos hallados en el Archivo Histórico de la Cancillería Argentina, nos habilitaron a abordar el tema y a respaldar las hipótesis de Ariel Armony con otras certezas, más moderadas, pero más firmes (Rostica, 2013; 2015; 2016).

Ariel Armony (1999), en el mismo trabajo, mencionó el tema central sobre el cual queremos indagar en este artículo. Señaló que la "naturaleza clandestina de la cooperación entre gobiernos [en la] empresa contrarrevolucionaria centroamericana" impulsó a los actores políticos a establecer vínculos transnacionales ad hoc y que "la inestable situación estimulaba la convergencia de gobiernos y actores no gubernamentales en torno del movimiento armado antisandinista" (p. 217). En ese apartado, Armony afirmó que "el programa extraterritorial argentino recibió apoyo financiero de la Liga Anticomunista Mundial (LAM) a 
través de la Confederación Anticomunista Latinoamericana", la rama latinoamericana de la Liga, y que la celebración del IV Congreso de la CAL realizado en septiembre de 1980 en Buenos Aires fue central en los procesos de intercambio entre Argentina y América Central. (Armony, 1999, pp. 238-240). Este tema nuevamente lo desarrolló en poquísimas páginas, a partir de algunas entrevistas ${ }^{5}$. Como su objetivo no era comprender la colaboración argentina en la lucha contrasubversiva en Guatemala, tampoco se enfocó en analizar este tema en específico.

En términos generales, todas las menciones existentes sobre la CAL aparecen ligadas a una dimensión de la colaboración argentina en Centroamérica: la de los asesores argentinos y la existencia del Grupo de Tareas Exterior. Este tema volvió a ser abordado desde el campo periodístico en el 2005, cuando hubo algunos avances basados en la desclasificación de documentos del Departamento de Estado estadounidense (Seoane, 2006; Barón, 2006; Santero, 2006; Godoy, 2008; Guerrero, 2005). Según estos, muchos de los militares argentinos que participaron en el Plan Cóndor entre 1975 y 1979 integraron luego la comitiva que siguió, entre 1978 y 1984, hacia Centroamérica para entrenar a los llamados "contras". Indican, por ejemplo, que el coronel José Osvaldo Riveiro fue el jefe del Grupo de Tareas Exterior en Honduras, quien reportaba directamente a Carlos Suárez Mason, jefe del Estado Mayor de la dictadura militar y presidente del IV Congreso de la CAL.

El Plan Cóndor ${ }^{6}$ fue un sistema clandestino transfronterizo que nació en América Latina a fines de 1973 y comienzos de 1974, tuvo

\footnotetext{
5 Ariel Armony entrevistó a los periodistas Juan José Salinas y Rogelio García Lupo.

6 Utilizamos la expresión de Plan Cóndor en vez de Operación Cóndor, pues es la que, finalmente, se ha usado en la sentencia del 27 de mayo de 2016 de la Causa N 1504 Plan Cóndor "Videla, Jorge Rafael y otros s/privación ilegal de la libertad personal"; N 1951 caratulada "Lobaiza, Humberto José Román y otros s/privación ilegal de libertad (art. 144 bis inc. $1^{\circ}$ del C.P.)"; No 2054 caratulada "Falcón, Néstor Horacio y otros s/asociación ilícita y privación ilegal de la libertad". El acta de clausura de la Primera Reunión Interamericana de Inteligencia Nacional, el acta fundacional del Plan Cóndor, con fecha del 21 de noviembre de 1975, habla de "sistema Cóndor".
} 
una fase de auge en 1976 y empezó a entrar en retroceso hacia 1978. Instituciones militares de Argentina, Bolivia, Brasil, Chile, Paraguay, Uruguay, Ecuador y Perú participaron de dicho sistema. Como producto de la doctrina de la seguridad nacional, cuyo centro neurálgico priorizó las fronteras ideológicas por sobre las territoriales, se articuló en torno a la idea de que contra la "amenaza subversiva" no debía haber barreras. Así, el Plan Cóndor puede definirse como un plan de coordinación supranacional de la represión (McSherry, 2012; Slatman, 2012; Visconti \& Rodríguez Díaz, 2012). Según J. Patrice McSherry, entre las características principales del Plan Cóndor está la utilización de organizaciones y redes de extrema derecha. Para la investigadora, el plan tuvo en su etapa final una conexión con Centroamérica (McScherry, 2009).

Los periodistas Francisco Martorell y Stella Calloni, en sus obras dedicadas al Plan Cóndor, también mencionan la extensión del mismo hacia América Central hacia fines de los años setenta y comienzos de los años ochenta. Martorell indicó que en esos tiempos Argentina encabezaba el grupo y su proyección hacia el exterior con el objeto de influir en la región y especialmente en Centroamérica (Martorell, 1999, pp. 184-185). En Guatemala, dijo Stella Calloni, "los servicios de inteligencia argentinos tenían una sede muy particular y desde allí trabajaban en toda la región, muchas veces bajo el disfraz de agencias periodísticas como fue el caso de una llamada Bairpress. Algunos de sus agentes llegaron a infiltrarse en las filas de refugiados de los distintos países del área para realizar espionaje" (Calloni, 2001, p. 223). Ambos periodistas fueron los primeros en trabajar con el acervo del Centro de Documentación y Archivo para la Defensa de los Derechos Humanos de Paraguay, al cual le dedicaron buena parte de sendos libros (Calloni, 2001, pp. 35-44). Sin embargo, no se enfocaron en la CAL.

En términos generales, los escasos abordajes que hay sobre la CAL no han utilizado el reservorio del Centro de Documentación y Archivo para la Defensa de los Derechos Humanos o los archivos de la policía stronista descubiertos en diciembre de 1992, en los que se hallan cientos de folios membretados por la CAL, es decir, elaborados por la propia organización. La excepción es el libro de Fernando López (2016), de 
reciente aparición, quien sistematizó algunos de los congresos de la organización (pp. 286-302). En estos documentos, como mostraremos, se mencionan las organizaciones y personas que integraban la red de extrema derecha, se encuentran las ponencias y las conclusiones de varios de los congresos y las conexiones de la red con los organismos de inteligencia de algunos de los países de la región. Los datos que de estas fuentes emanan nos permiten enmarcar otros datos hallados en el Archivo Histórico de la Cancillería argentina y fuentes hemerográficas. Este material nos permite empezar a reconstruir las condiciones de posibilidad para la transferencia de recursos de Argentina hacia Guatemala a través de las conexiones civiles, secretas, informales y clandestinas, especialmente a través de la Confederación Anticomunista Latinoamericana. A diferencia de los trabajos ya citados que enfocan el problema a partir del estudio de los asesores argentinos en Centroamérica o de la extensión del Plan Cóndor en el istmo, en esta investigación abordamos el movimiento inverso: observamos la participación de la extrema derecha guatemalteca en la red latinoamericana de la CAL y sus conexiones con Argentina.

\section{El anticomunismo en Guatemala. Civiles y militares en la lucha contra la subversión}

En Guatemala, las organizaciones anticomunistas surgieron a partir de 1944 para cuestionar al gobierno reformista y democrático de Juan José Arévalo (1945-1951) y se radicalizaron durante el gobierno de Jacobo Árbenz (1951-1954). Las principales fueron la Asociación Cívica de Defensa contra el Comunismo que sentó las bases del Partido de Unificación Anticomunista (PUA) y una tendencia en el interior del Frente Popular Libertador ${ }^{7}$ liderada por el futuro presidente Mario

\footnotetext{
El Frente Popular Libertador fue un partido creado cuando Jorge Ubico renunció. Tiene sus orígenes en las reiteradas solicitudes por la autonomía universitaria que se hicieron a Ubico y que devinieron en la huelga general de estudiantes y magisterio hacia el final crítico de su gobierno. Su dirección estuvo formada íntegramente por estudiantes y sus afiliados fueron la juventud universitaria, especialmente de Derecho y Medicina. Junto a Renovación Nacional, el FPL convocó a Juan José Arévalo para candidato a la presidencia, quien triunfó con más del $86 \%$ de los votos emitidos.
} 
Méndez Montenegro, Mario Sandoval Alarcón, Lionel Sisniega Otero y el coronel Francisco Javier Arana, que luego se agrupó en el Comité de Estudiantes Universitarios Anticomunistas (Gordillo Castillo, 2004, pp. 87-102). Cuando el aglutinamiento del bloque anticomunista alcanzó al Ejército inició el final del proceso revolucionario conducido por Arévalo y Árbenz. La gran disputa para integrar el Consejo Superior de Defensa Nacional estaba entre el coronel Francisco Javier Arana y el capitán Jacobo Árbenz, los dos cabecillas del alzamiento militar de 1944 y miembros de la Junta Revolucionaria de Gobierno. La muerte incidental de Arana en esta coyuntura y el derrocamiento de la rebelión militar de sus sucesores en 1949; el triunfo electoral de Árbenz con el 68\% de los votos en 1950; la legalización del partido comunista de Guatemala (Partido Guatemalteco del Trabajo) y la presencia de comunistas en el Congreso, en la dirección de la Central General de Trabajadores Guatemaltecos y en la redacción de la reforma agraria en plena Guerra Fría marcaron un mojón en la historia de Guatemala (Pinto Recinos, 2004, pp. 43-44; Fortuny, 1977, p. 57). Fueron los acontecimientos históricos que explican la operación encubierta fraguada por la Agencia Central de Inteligencia que se denominó operación PBSUCCESS (Gleijeses, 2008; Cullather, 2002; Doyle \& Kornbluh, s.f.; Grandin, 2001), la traición de algunos altos jefes del Ejército de Guatemala y finalmente la renuncia de Jacobo Árbenz el 27 de junio de 1954.

El coronel Carlos Castillo Armas y el ejército liberacionista entraron triunfantes a la ciudad de Guatemala el 3 de julio de 1954. La Junta de Gobierno, que presidió Castillo Armas, se proclamó acatando los deseos del pueblo "para erradicar definitivamente el comunismo del suelo patrio" y sancionó la Ley Preventiva Penal contra el Comunismo, la cual declaraba "fuera de la ley el comunismo en todas sus formas, actividades y manifestaciones" e indicaba que el conocimiento, substanciación y sentencia correspondía a los tribunales militares?. También creó el Comité de Defensa Nacional contra el Comunismo mediante el Decreto $\mathrm{N}^{\circ} 23$, según el cual los "elementos marcadamente comunistas

\footnotetext{
8 Junta de Gobierno, "Estatuto Político de la República de Guatemala", 10 de agosto de 1954.

9 Junta de Gobierno, "Ley preventiva penal contra el comunismo", Decreto No 59, 24 de agosto de 1954.
} 
del régimen anterior [...] constituyen un peligro para el desarrollo normal de la actividad del país [y que] uno de los fines primordiales del movimiento de liberación fue, es y será la extirpación total del comunismo y los males que trae como secuela obligada". Este Decreto fue derogado y reemplazado por el Decreto $\mathrm{N}^{\circ} 187$ que señalaba como conveniente "mantener las instituciones encargadas de combatir y erradicar el comunismo dentro del territorio nacional" ". El Comité estableció un registro "organizado técnicamente, de todas las personas que en cualquier forma hayan participado en actividades comunistas" y más tarde el establecimiento de la pena de muerte por actividades de resistencia susceptibles de ser consideradas como comunistas. Según la prensa nacional, entre julio y noviembre de 1954, eran 72 mil personas las que habían sido listadas en el registro de comunistas. Conjuntamente se emitieron quince decretos dirigidos a prohibir y perseguir las actividades comunistas. El 28 de febrero de 1956 entró en vigor el Decreto No 553 que creó la Dirección General de Seguridad Nacional, la cual reemplazó al Comité de Defensa Nacional contra el Comunismo. Esta Dirección tenía jurisdicción sobre la Policía Nacional. La Constitución de 1945 fue reemplazada por el Estatuto Político de la República de Guatemala ${ }^{11}$ y luego por la nueva Constitución de la República de Guatemala sancionada el 2 de febrero de 1956. Esta, a diferencia de todas las constituciones anteriores, prohibió "la organización o funcionamiento de todas aquellas entidades que propugnen la ideología comunista" (artículos 23 y 54) y consignó que "toda acción comunista individual o asociada es punible” (artículo 62) ${ }^{12}$.

10 Junta de Gobierno, "Comité de Defensa Nacional contra el comunismo", Decreto $\mathrm{N}^{\mathrm{o}} 23,19$ de julio de 1954. Derogado y reemplazado por Presidente Constitucional de la República, "Comité de Defensa Nacional contra el comunismo", Decreto No 187, 24 de diciembre de 1954.

11 Junta de Gobierno, "Estatuto Político de la República de Guatemala", 10 de agosto de 1954, en Recopilación de Leyes, República de Guatemala, pp. 52-56.

12 El primer Partido Comunista de Guatemala se fundó en 1922 y sufrió la persecución y el encarcelamiento constante de sus militantes. A fines de 1931, Jorge Ubico desencadenó una ola de arrestos de prácticamente todos sus miembros y en febrero de 1932 dio inicio a un proceso contra el PCG bajo un tribunal militar (Taracena Arriola, 1989, p. 61). Posteriormente, Juan José Arévalo, declaradamente anticomunista, puso trabas a la libertad de opinión y expresión y no fue él quien legalizó el partido, vuelto a fundar en 1949 como Partido Guatemalteco 
Castillo Armas se afincaba en el Movimiento Democrático Nacionalista (MDN), un partido fundado en 1955, que procuraba reunir a algunas de las organizaciones anticomunistas mencionadas (Comité de Estudiantes Universitarios Anticomunistas, Ejército de Liberación Nacional, entre otras) y cuyo dirigente principal era Mario Sandoval Alarcón (Demyk, 1994, p. 113). El asesinato de Castillo Armas al interior de la Casa Presidencial generó una crisis política que desembocó en la elección del general Miguel Ydígoras Fuentes en 1958. En esa coyuntura nacieron el Comité Coordinador de Asociaciones Agrícolas, Comerciales, Industriales y Financieras (CACIF) y la fundación del Movimiento de Liberación Nacional (MLN), que reemplazó al MDN. Son infinitos los analistas quienes afirman que, desde sus inicios, el MLN estuvo vinculado a grupos paramilitares y que Mario Sandoval Alarcón ejerció un dominio absoluto del partido y un control total de sus adversarios (Gordillo Castillo, 2004, p. 102).

En lo sucesivo, el MLN participó de la gran mayoría de los pactos y acuerdos políticos de lucha contra el comunismo. Para empezar, durante la misma presidencia de Ydígoras Fuentes, específicamente en 1960, cuando se objetivó un pacto entre los partidos de centro derecha por "la lucha ideológica y material en forma categórica y permanente contra el comunismo"13 (Villagrán Kramer, 1993, pp. 356-357). Después, en el golpe militar del 30 de marzo de 1963, ideado por los dieciséis más altos jefes militares y encabezado por el coronel Enrique Peralta Azurdía, quienes asumieron transitoriamente el gobierno con el fin de "evitar una inminente guerra civil y la instauración de un régimen comunista" "14 (Villagrán Kramer, 2004,

del Trabajo. A pesar de la persecución ideológica y partidaria, ninguna de las constituciones previas a la de 1956 explicitó la prohibición del comunismo en todas sus formas.

13 Durante ese gobierno se sancionó la Ley de Defensa de la Instituciones Democráticas, Decreto No 1424 del Congreso de la República de Guatemala, que reemplazó a la Ley Preventiva Penal Contra el Comunismo. Su nueva sanción definió al comunismo como una doctrina internacional "incompatible con nuestro ordenamiento jurídico". Como consecuencia prohibió "toda clase de entidades de ideología comunista en el territorio nacional". El listado de delitos que la ley establecía serían juzgados por tribunales militares. Jefe del Gobierno de la República, Decreto-Ley Nº 9, 10 de abril de 1963.

14 Jefe de Gobierno de la República, "Carta Fundamental de Gobierno", Decreto-ley No 8, 10 de abril de 1963. 
p. 50). El golpe contó con el apoyo de partidos civiles, como del MLN, del Partido Revolucionario (PR) y de la Democracia Cristiana (DC), los cuales, como ya se mencionó, habían pactado coordinación, unidad de acción y defensa común contra el comunismo a finales de 1960. Si bien dicho pacto se rompió en 1965, estos partidos políticos participaron en las contiendas electorales subsiguientes (Villagrán Kramer, 1993, pp. 355-406). Luego, el Ejército controló el poder por intermedio de un partido de su propia creación, el Partido Institucional Democrático (PID) fundado por el coronel Enrique Peralta Azurdía en 1966, bajo un pacto con el PR primero y en alianza con el MLN después (Villagrán Kramer, 1993). Cabe señalar que entre 1965 y 1966 se desplegó la "operación limpieza", la primera desaparición selectiva forzada a gran escala en Latinoamérica, que consistió en cateos casa por casa de los "subversivos" a partir de información que brindaban los servicios de inteligencia ${ }^{15}$. Abiertas las elecciones para el año 1966, con un restringido repertorio de partidos políticos, pues la Constitución de 1965 limitaba la participación de aquellos asociados al comunismo, sumado a un deterioro de la imagen del Ejército, el Partido Revolucionario ganó con su candidato Julio César Méndez Montenegro. Sin embargo, al ser el único civil de los tres candidatos (PID y MLN), fue impelido a suscribir otro pacto secreto con los coroneles de la alta cúpula militar para la lucha contra el comunismo y la ratificación de la designación de militares en todas las gobernaciones departamentales ${ }^{16}$.

Entre 1971 y 1978 se consolidó la alianza entre el Ejército, los partidos políticos (el MLN y el PID) y los sectores empresariales (CACIF), a fin de crear una fachada democrática caracterizada por elecciones periódicas de las que quedaban excluidos los partidos de izquierda ${ }^{17}$. Durante la presidencia del coronel Carlos Manuel Arana Osorio (1970-1974), Mario Sandoval Alarcón presidió el Congreso de la

\footnotetext{
15 Secuestro y ejecución de 33 miembros del PGT, las FAR y otros grupos de izquierda. Véase Comisión para el Esclarecimiento Histórico (1999, pp. 89-98, anexo 1).

16 La reproducción del pacto suscrito entre el Ejército de Guatemala y el Partido Revolucionario en 1966 está disponible en Comisión para el Esclarecimiento Histórico (1999, p. 286, tomo 1, apéndice 19) y Gramajo Morales (1995, pp. 462-464).

17 Se utilizó un presidente fuerte acompañado de un ministro de Defensa que sería el próximo candidato a la Presidencia.
} 
República (1970-1974). El MLN, además, obtuvo cargos importantes dentro del gabinete. En las elecciones de 1974 triunfaron el general Kjell Eugenio Laugerud García como presidente y Mario Sandoval Alarcón como vicepresidente (1974-1978). Durante esos ocho años, el MLN gobernó Guatemala junto al partido de los militares. Para las elecciones de 1978 la alianza PID-MLN se quebró y el MLN perdió. Esto ha servido en reiteradas oportunidades para desvincular al partido de extrema derecha y al CACIF de la acción represiva de las Fuerzas Armadas guatemaltecas entre 1978 y 1982. A nuestro juicio, el MLN, a pesar de situarse en la oposición política al gobierno del general Romeo Lucas García (1978-1982), se unió al mismo para enfrentar al "enemigo interno", lo que se consideraba un asunto prioritario y de Estado, y desde ese lugar gestionó recursos para la lucha contra la subversión. Los resultados de nuestra investigación apuntan a considerar que hubo una posible transferencia de recursos de Argentina hacia Guatemala a través de conexiones civiles y militares — en gran medida informales, secretas y clandestinas - entre el MLN, la CAL y los militares de ambos países. En este periodo se había priorizado la modernización operativa del Ejército, especialmente la inteligencia, y el terrorismo de Estado fue permanente, aunque implementado de forma selectiva (CEH, 1999, pp. 147-148).

\section{Las conexiones civiles y militares a través de la CAL}

Durante 1975, dos importantes figuras del MLN habían recibido la orden Libertador San Martín en Gran Cruz, en Argentina: Armando Sandoval Alarcón, embajador extraordinario y plenipotenciario de Guatemala en Argentina (Decreto No 232, 30 de enero de 1975) y Mario Sandoval Alarcón, vicepresidente de su país (Decreto No 4032 , 23 de diciembre de 1975). Ese año había sido de singular importancia para Argentina. Tras la muerte de Juan Domingo Perón en 1974, Isabel Martínez había asumido la presidencia y se había rodeado de un grupo de fieles, encabezado por José López Rega, quien como ministro de Bienestar Social lideraba la organización paraestatal y 
parapolicial Triple $\mathrm{A}^{18}$. Durante ese año, mientras se condecoraba a líderes de organizaciones de extrema derecha de Guatemala y la violencia de la Triple A se acrecentaba, también se institucionalizaba la violencia represiva del Estado argentino. En efecto, con el Operativo Independencia en la provincia de Tucumán, en 1975, se había iniciado una política institucional de desaparición forzada de personas. El 6 de octubre de 1975 se dictaron los llamados decretos de aniquilamiento 2770, 2771 y 2772 mediante los que se puso de manifiesto el objetivo de aniquilar el accionar de los elementos subversivos en todo el país ${ }^{19}$.

En plena dictadura cívico-militar, Mario Sandoval Alarcón fue recibido por el presidente de la Junta Militar golpista, Jorge Videla, entre el 27 y el 31 de julio de $1977^{20}$. El 18 de septiembre de 1979, cuando el MLN ya era oposición al gobierno de Guatemala, el líder anticomunista se reunió con el embajador argentino en Guatemala. El cable mediante el cual el embajador informó a la Cancillería argentina el contenido de la reunión indicó que Mario Sandoval Alarcón, con motivo de la reunión de los Ejércitos Americanos, "entregaría con destino a [los] ejércitos [de los] países del Cono Sur [un] informe completo sobre [la] subversión, situación global centroamericana y la de Nicaragua" y corroboró la acción conjunta entre las Fuerzas Armadas de Guatemala y el MLN"21. Para el gobierno argentino, la "cohesión firme contra

18 Para ampliar este tema véase, entre otros, De Riz (1981), Paino (1984), González Janzen (1986), Feinmann (1987), Sigal y Verón (1988), Marín (1996), Larraquy (2007), Izaguirre (2009), Gasparini (2011) y Rostica (2011).

19 Para completar el cuadro normativo hay que mencionar, también, la Directiva 1/75 del Consejo de Defensa y las reglamentaciones: Directiva 404, Orden Parcial 405, Placintara y Plan de Capacidades de la Fuerza Aérea.

20 Cable secreto, de Tiscornia, EGUAT a América Central-política-informaciones, 9 de junio de 1980, Archivo Histórico del Ministerio de Relaciones Exteriores y Culto de Argentina (MREC), cForti, Guatemala, cr409-410.

21 Según el documento, Mario Sandoval Alarcón dijo que: “existía cohesión en [las] Fuerzas Armadas con las cuales 'estamos trabajando conjuntamente y de común acuerdo”'. Según el embajador argentino, el hecho se confirmó cuando se les acercó "el Jefe del Estado Mayor del Ejército General Guevara que continuó en su presencia durante la conversación en la cual [el] exVicepresidente [Mario Sandoval Alarcón] manifestó que [el] informe aludido lo vendrían a buscar a Guatemala en los próximos días". Cable secreto, de Tiscornia, EGUAT a latina-informaciones, 19 de septiembre de 1979, MREC, Caja AH/0060, Sección 71-comunicaciones, "Guatemala. vol. 89", cr444-446. 
el comunismo" del Ejército guatemalteco y de las Fuerzas Armadas en general era un elemento fundamental ${ }^{22}$. Mucho mejor si a esta se sumaba el apoyo que veían de Mario Sandoval Alarcón, a pesar de que se presentaba políticamente en la oposición. Al menos para la embajada argentina en Guatemala, civiles y militares actuaban en ese país conjuntamente. Recordemos que a esa XIII Conferencia de los Ejércitos Americanos (2 de noviembre de 1979) viajaron el viceministro de Defensa de Guatemala y el director de Inteligencia Callejas y Callejas ${ }^{23}$ y que fue precisamente la reunión en la que la delegación argentina abogó por la Doctrina Viola, la cual formalizó el supuesto derecho de los ejércitos latinoamericanos a actuar independiente o colectivamente en todo país de la región donde se produjeran movimientos revolucionarios por la inacción de Estados Unidos. Sandoval pidió volver a entrevistarse con el presidente argentino Videla en junio de 1980 y a pronunciar conferencias sobre anticomunismo en el país ${ }^{24}$. Visitó nuevamente Argentina cuando Buenos Aires fue sede del IV Congreso de la CAL, en septiembre del mismo año. Si bien desconocemos los contenidos de las reuniones, tenemos certezas sobre sus obsesiones.

La CAL y sus Congresos constituyeron una red latinoamericana de extrema derecha que apoyó y se articuló estrechamente, aunque no solamente, con las Fuerzas Armadas de cada uno de los países en los que se ejercían sendas dictaduras y gobiernos militares para la represión interna. Consideramos apropiado caracterizar a la red en la extrema derecha porque su ideología fue tan visceralmente anticomunista que abogó por la supresión del comunismo como alternativa política en las democracias representativas de la región y por su eliminación mediante

\footnotetext{
22 Nota secreta, de Tiscornia al director general de Política, EGUAT, 1 de febrero de 1979, MREC, cForti, Guatemala, nr41. Cable secreto, de Tiscornia, EGUAT a latina-derechos humanos- subsecretaría relaciones exteriores-política-organismos-informaciones, 6 de mayo de 1980, MREC, cForti, Guatemala, cr314-319.

23 Cable ordinario, de Tiscornia, EGUAT a latina-informaciones, 2 de noviembre de 1979, MREC, Caja AH/0060, Sección 71-comunicaciones, “Guatemala. vol. 89”, cr519.

24 Cable ordinario, de Tiscornia, EguAT a América Central-América del Sur-políticaceremonial-informaciones, 2 de junio de 1980, MREC, cForti, Guatemala, cr395.
} 
el uso de la violencia política institucional y no institucional al incluir dentro de la red a organizaciones paramilitares y terroristas.

La CAL fue creada entre el 28 y el 29 de agosto de 1972 en México, en el marco de la sexta asamblea de la Liga Anticomunista Mundial (WACL), durante una serie de sesiones secretas (López Macedonio, 2010, p. 154). Esta tuvo un secretario general y un consejo coordinador. Según los documentos con los que contamos, el secretario general fue Rafael Rodríguez (México) y el subsecretario general Antonio Carlos Alum (Paraguay). Es importante señalar que este último era el director de la DNET (O DNAT), la Dirección Nacional de Asuntos Técnicos, una dependencia del Ministerio del Interior de Paraguay creada a fines de la década del cincuenta con la misión de combatir el comunismo. Stella Calloni explica que Campos Alum era el director de la Policía Técnica paraguaya, acusado de torturar personalmente a los prisioneros y de otras graves violaciones a los derechos humanos (Calloni, 2001, pp. 219 y 222).

Esta confederación de extrema derecha organizaba congresos secretos y semipúblicos. Los primeros fueron los llamados Congresos Sección Partidos Políticos y Organizaciones Militares, cuyo secretario general fue en un comienzo el mexicano Humberto Dávalos Herreros e integraba a los miembros regulares; los segundos fueron los Congresos Sección Miembros Asociados, cuyo secretario general fue el mexicano Rafael Rodríguez. A estos asistían delegados por la mayoría de los países de la región y se organizaban en comisiones ${ }^{25}$.

Delegaciones de Guatemala participaron de la asamblea que dio nacimiento a la CAL y de los sucesivos congresos (López Macedonio, 2010, p. 154). Hemos podido constatar que en el II Congreso Secreto, realizado en Asunción entre el 28 de mayo y el 1 de junio de 1973, participó Antonio Sandoval Martínez del MLN, primo de Mario Sandoval Alarcón ${ }^{26}$. En la reunión del Consejo Coordinador

\footnotetext{
25 Para el III Congreso de la CAL, todos los países de América Latina enviaron representantes salvo Panamá, Jamaica, Hatí y Antillas menores. En el IV Congreso hubo una delegación más.

26 Informe al ministro del Interior, II Congreso Secreto, Confederación Anticomunista
} 
de la CAL, realizada en Guadalajara entre el 10 y el 12 de julio de 1974, participaron Roberto Cordón (quien fue presidente del CACIF), como subsecretario de Asuntos Campesinos de la Zona Norte o, como aparece en otro documento, como secretario de Defensa de la Propiedad Agrícola de la Zona Norte, y Fernando Ibarra, como presidente de la Liga Anticomunista Juvenil Mundial ${ }^{27}$. En el III Congreso de la CAL, realizado en Asunción entre el 28 y 30 de marzo de 1977, participaron Roberto Cordón, Guillermo Valdez Tible (diputado del PID-MLN y luego del PAN) y Alfredo López Estrada ${ }^{28}$. En el XII Congreso de la Liga Anticomunista Mundial, realizado en Asunción entre el 22 y el 27 de abril de 1979, participó Roberto Cordón ${ }^{29}$, y en el IV Congreso, realizado en Buenos Aires entre el 2 y 4 de septiembre de 1980, participó Mario Sandoval Alarcón. La Secretaría General de la CAL incluso le solicitó a todos sus miembros que enviasen mensajes de congratulación a Mario Sandoval Alarcón cuando fue elegido vicepresidente de Guatemala. La organización esperaba que el nuevo gobierno "con apoyo del pueblo realice con éxitos sus planes de engrandecimiento [de la] Nación y mejoramiento [de] campesinos [y] obreros y demás sectores sociales aplastando enemigos internos de la patria con apoyo del pueblo y de las Fuerzas Armadas" ${ }^{30}$.

Latinoamericana, 28 de mayo a $1^{\circ}$ de junio de 1973, Centro de Documentación y Archivo para la Defensa de los Derechos Humanos (CDADDH), Dirección Nacional de Asuntos Técnicos, 00108F2069.

27 Informe, Reunión del Consejo Coordinador de la Conferencia Anticomunista Latinoamericana (CAL), 10 al 12 de julio de 1974, Guadalajara, México, CDADDH, Dirección Nacional de Asuntos Técnicos, R108F2055/6; Circular Nro. 3/74, de Rafael Rodríguez, secretario General, a todos los miembros y colaboradores de la Confederación Anticomunista Latinoamericana, 16 de agosto de 1974, CDADDH, Dirección Nacional de Asuntos Técnicos, R0094F1108-12.

28 Delegaciones extranjeras, CDADDH, Dirección Nacional de Asuntos Técnicos, R0094F0029-30.

29 Ponencia de la delegación de Guatemala, Partido Movimiento de Liberación Nacional, XXII Congreso de la Liga Mundial Anticomunista, Asunción, 23-27 de abril de 1979, CDADDH, Dirección Nacional de Asuntos Técnicos, R108F1588 y Listado de nombres, países y ponencias, CDADDH, Dirección Nacional de Asuntos Técnicos, R108F1621.

30 Circular, de Rafael Rodríguez a miembros de la Confederación Anticomunista Latinoamericana, 9 de marzo de 1974, CDADDH, Dirección Nacional de Asuntos Técnicos, 00108F1749. 
La CAL se coordinó con diferentes organismos de inteligencia latinoamericanos. Ya he mencionado el altísimo cargo que Antonio Campus Alum tenía dentro de la organización. La misma también la integraba el teniente coronel Luis Benedicto Rodríguez de El Salvador ${ }^{31}$, quien era nada menos que el líder de ORDEN, una extensa red de control y vigilancia en las zonas rurales que delataba, perseguía y actuaba bajo ANSESAL, el Servicio Nacional de Inteligencia de El Salvador. En los setenta, ANSESAL había tomado control de ORDEN, ambas trabajaban conjuntamente y crearon grupos clandestinos conocidos como escuadrones de la muerte (Ramírez Fuentes, 2016, p. 11). En el II Congreso Secreto "la delegación de Brasil ofreció a la delegación del Paraguay, en forma privada, la más amplia colaboración en informaciones, medios materiales y asesoramiento técnico" 32 . Este ofrecimiento no es menor si consideramos que en Brasil, a partir del golpe de Estado de 1964, se creó el Servicio Nacional de Informaciones (SNI), un órgano de la Presidencia que actuaba como asesor del Consejo de Seguridad Nacional, que en 1971 creó la Escuela Nacional de Información, constituyéndose en la más importante agencia de inteligencia nacional e internacional (Stepan, 1988, p. 39). En ese mismo congreso se designó al doctor Rubén Darío Ossorio como jefe del Servicio Latinoamericano de Inteligencia y al doctor Antonio Campos Alum como jefe del Departamento Técnico Latinoamericano de Asesoría y Ayuda en la lucha contra las guerrillas y el terrorismo ${ }^{33}$.

A la reunión del Consejo Coordinador de la CAL de julio de 1974 concurrieron el salvadoreño Adolfo Cuéllar y el uruguayo Martín Gutiérrez. Según Holly Sklar, "Cuéllar es recordado por antiguos oficiales del Ejército salvadoreño 'como un hombre que se aparecía

\footnotetext{
31 Informe sobre el Segundo Congreso Secreto de la Confederación Anticomunista Latinoamericana, de Antonio Campos Alum al ministro del Interior, 28 de mayo al 1 de junio de 1973, CDADDH, Dirección Nacional de Asuntos Técnicos, R00094F1461.

32 Informe sobre el Segundo Congreso Secreto de la Confederación Anticomunista Latinoamericana, de Antonio Campos Alum al ministro del Interior, 28 de mayo al 1 de junio de 1973, CDADDH, Dirección Nacional de Asuntos Técnicos, R00094F1461.

33 Informe sobre el Segundo Congreso Secreto de la Confederación Anticomunista Latinoamericana, de Antonio Campos Alum al ministro del Interior, 28 de mayo al 1 de junio de 1973, CDADDH, Dirección Nacional de Asuntos Técnicos, R00094F1460.
} 
en los centros de interrogación y suplicaba permiso para torturar a los prisioneros", una persona clave de los servicios de inteligencia del país centroamericano (González Ruiz, 2006, p. 169). El psiquiatra uruguayo Martín Gutiérrez era un “alto asesor” de la dictadura y uno de los artífices del plan de aplicación de la tortura psicológica ${ }^{34}$. En dicha reunión, Gutiérrez informó que en el mes de septiembre de 1974 se realizaría en Montevideo un Foro de Empresarios organizado con el asesoramiento de la Dirección de Inteligencia del Gobierno uruguayo. Gutiérrez sugirió que a ese foro fueran algunos miembros del Consejo Coordinador para ir obteniendo colaboración del sector empresarial en la lucha anticomunista ${ }^{35}$. En el III Congreso Secreto de la CAL se dispuso que "todos los miembros quedan obligados a procurar las mayores aportaciones de sus gobiernos o de particulares para aumentar las reservas del fondo" 36 .

El III Congreso de la CAL fue abierto, entre otros, por Gustavo Leigh Guzmán, comandante en jefe de la Fuerza Aérea y miembro de la Junta Militar de Gobierno que derrocó a Salvador Allende en Chile. Leigh Guzmán se acercaba trayendo:

el mensaje de mi pueblo y de la Junta Militar de mi país a esta Asamblea. Este es un mensaje de esperanza, pero a la vez, es un compromiso de Chile. Ante ustedes declaro responsablemente que el Gobierno de mi Patria no transará en sus ideales libertarios, que las Fuerzas Armadas de mi país, institucionalmente unidas, extirparán la pobreza de nuestra sociedad y entregarán al mundo como un ejemplo, la decisión indomable de triunfar ${ }^{37}$.

\footnotetext{
34 Rodríguez, Roger, 2 de junio de 2016, "Uruguay: cuentas de impunidad", Resumen Latinoamericano. Disponible en http://www.resumenlatinoamericano.org/2016/06/08/ uruguay-cuentas-de-impunidad/

35 Informe, Reunión del Consejo Coordinador de la Confederación Anticomunista Latinoamericana, Guadalajara, México, 10 al 12 de julio de 1974, p. 4., CDADDH, Dirección Nacional de Asuntos Técnicos, R108F2058.

36 Resoluciones aprobadas por la comisión de partidos políticos, III Congreso de la Confederación Anticomunista Latinoamericana, Brasilia, 29 al 2 de diciembre, CDADDH, Dirección Nacional de Asuntos Técnicos, R108F0959. Cursivas fuera del original.

37 Discurso del general Gustavo Leigh Guzmán, comandante de la Fuerza Aérea y miembro
} 
En los diferentes Congresos de la CAL se producían declaraciones a favor de los gobiernos nacionales anticomunistas. En la apertura del III Congreso, el secretario general Rafael Rodríguez sostuvo que en América Latina el comunismo había retrocedido, lo que probaba la fortaleza de "nuestras defensas y de nuestras reservas si se emplean a fondo. Muerden el polvo los rojos en Brasil, en Uruguay, en Argentina, en Chile, en Paraguay, en Nicaragua, en El Salvador y en Guatemala". Mientras que recordó al expresidente guatemalteco Carlos Castillo Armas como uno de los líderes que se fueron, saludó enérgicamente al presidente general Kjell Eugenio Laugerud García del MLN, entre Pinochet, Geisel, Somoza y Stroessner ${ }^{38}$. La comisión plenaria del III Congreso ya había decidido apoyar a "los gobiernos de Argentina, Brasil, El Salvador, Guatemala y Uruguay por su actitud respecto a la administración Carter [y] a los gobiernos que mantienen una política nacionalista y anticomunista" 39 . Este Congreso dejó una declaración final en la que volvió a enfatizar el nacionalismo y el anticomunismo que ejercían defendiendo el principio de no intervención y autodeterminación de los pueblos para denunciar el condicionamiento de la ayuda militar y económica de Estados Unidos hacia los "estados chileno, guatemalteco, salvadoreño, argentino, uruguayo y brasileño" por supuestas violaciones a los derechos humanos cometidas por sus gobiernos y Fuerzas Armadas. La declaración enfatizó el ejercicio de legítima defensa con la agresión del comunismo: "solamente ejerciendo acciones militares y psicopolíticas inteligentes y audaces se podrá evitar la reiteración de desgracias como las del noble pueblo cubano" ${ }^{40}$. Consideraba que era un "deber de todos contribuir

de la Junta de Gobierno de Chile, en la apertura del III Congreso de la CAL, CDADDH, Dirección Nacional de Asuntos Técnicos, R0094F0023.

38 Escritos varios / correspondencia, de Rafael Rodríguez, discurso de apertura, III Congreso, Confederación Anticomunista Latinoamericana, Asunción, Paraguay, 28 al 30 de marzo de 1977, CDADDH, Dirección Nacional de Asuntos Técnicos, 00094F0018-0020.

39 Escritos varios / correspondencia, índice, III Congreso, Confederación Anticomunista Latinoamericana, Asunción, Paraguay, 28 al 30 de marzo de 1977, CDADDH, Fondo Dirección Nacional de Asunto Técnicos, 00094F0040-0041.

40 Declaración final, III Congreso General de la Confederación Anticomunista Latinoamericana, Asunción, 30 de marzo de 1977, CDADDH, Dirección Nacional de Asuntos Técnicos, R0094F0066. 
a la causa de su libertad, siguiendo en dicho aspecto los heroicos ejemplos que han dado al mundo entero los gobiernos y las Fuerzas Armadas de Chile, Nicaragua, Guatemala, El Salvador, Brasil, Uruguay, Argentina y Paraguay". Concluía agradeciendo la presencia de Alfredo Stroessner y de Gustavo Leigh Guzmán ${ }^{41}$. Esta declaración ilumina el posicionamiento de la CAL frente a la política de Estados Unidos, realza su autonomía respecto del país del norte y muestra que, en determinados momentos, estas organizaciones y varios de los gobiernos nacionales actuaron y se coordinaron sin su anuencia.

El IV Congreso de la CAL se realizó en el Teatro Municipal General San Martín de Buenos Aires el 2 de septiembre de 1980, con aproximadamente doscientos delegados de veinte países de América Latina. En perspectiva comparada puede afirmarse que fue el congreso de la CAL de mayor magnitud y a través del cual puede haberse materializado una transferencia de recursos de Argentina hacia Guatemala. Asistió al acto el jefe de la Policía Federal, el general Juan Bautista Sasiaiñ, detenido por el robo de bebés durante la dictadura, y oficiales en actividad de las tres Armas.

Para este Congreso, la CAL recibió mensajes de adhesión de los presidentes argentino, paraguayo, boliviano y del comandante en jefe del Ejército uruguayo ${ }^{42}$. Las veinte delegaciones que asistieron condenaron duramente la política estadounidense de derechos humanos y su presidente, el jefe del Estado Mayor del Ejército argentino y del Batallón 601 de Inteligencia del Ejército, Carlos Suárez Mason, conminó a dar soluciones prácticas y acciones concretas a la conspiración que, según indicó el secretario general de la CAL, "no viene solo de Moscú o de La Habana, sino que cuenta con bases de apoyo en Washington, Nueva York y cómplices en Venezuela, Panamá, Costa Rica y México" "43. En su discurso señaló que el congreso

\footnotetext{
41 Declaración final, III Congreso General de la Confederación Anticomunista Latinoamericana, Asunción, 30 de marzo de 1977, CDADDH, Dirección Nacional de Asuntos Técnicos, R0094F0065-68.

42 "Adhesión de Videla al Congreso Anticomunista", 2 de septiembre de 1980, Clarin, p. 8.

43 El Batallón había nacido el 1 de enero de 1968. La directiva 1/75 del Consejo de Defensa
} 
puede ser tan necesario para el esclarecimiento, la actualización de la información global y la determinación de las estrategias, políticas y procedimientos recomendables para la prosecución de la defensa del inestimable patrimonio espiritual y material del mundo libre, comprometido en estos años por la presencia de la filosofía marxista y sus consecuencias.

El guatemalteco Mario Sandoval Alarcón tildó a dichos países considerados cómplices de "tontos útiles al servicio del comunismo internacional" y a Carter de "el más nefasto de los mandatarios de Estados Unidos" y de "traicionar al presidente Anastasio Somoza"44. Luis Ángel Lagos, del Partido de Conciliación de El Salvador, expresó que "estamos en permanente lucha bajo el lema de que el único comunista bueno que va a haber en el país va a ser el comunista muerto"45.

En la conferencia de prensa del secretario general, el mexicano Rafael Rodríguez, se informó que en el congreso se habían presentado sesenta ponencias que abarcaron dos tópicos: "la agresión soviética en América Central y el Caribe [y] la actuación de algunos gobiernos de América Latina y otras organizaciones internacionales como cómplices de esa agresión”. La CAL volvía a ratificar públicamente, en definitiva, su oposición tajante a la política de James Carter que había recortado todo tipo de apoyo a los países que violaban los derechos humanos y reinventaba una comunidad latinoamericana

señaló que el Ejército conduciría con responsabilidad primaria el esfuerzo de inteligencia de la comunidad informativa a fin de lograr una acción coordinada e integrada, tarea que se realizaría en absoluto secreto. La actividad de inteligencia se centralizaría desde la Jefatura II del Estado Mayor General del Ejército del Comando General del Ejército. Esa Jefatura II definió como órgano ejecutor de dicha centralización al Batallón de Inteligencia 601. La Central de Reunión del Batallón de Inteligencia 601 estaba integrada por los servicios de inteligencia de la Fuerza Aérea, la Armada, Institutos Penales, Superintendencia de Seguridad Federal, Prefectura, SIDE, entre otros, y por personal del Batallón 601. Véase Programa Verdad y Justicia (2015, p. 4).

44 "Adhesión de Videla al Congreso Anticomunista", 2 de septiembre de 1980, Clarín, p. 8 y "Denuncian anticomunistas una conspiración marxista contra Latinoamérica dirigida desde Cuba y la URss", $1^{\circ}$ de septiembre de 1980, Uno Más Uno.

45 "Fue inaugurado el Cuarto Congreso Anticomunista", 2 de septiembre de 1980, La Nación, p. 10. 
de extrema derecha bajo la cual fluyeran los recursos y apoyos a las luchas contrasubversivas de la región. En este sentido, Rodríguez afirmó que "se adoptaron acuerdos que se traducirán en medidas de trabajo para contrarrestar esa ofensiva" ". Según la prensa, fue un evento "que podría anteceder a algún organismo de integración política del bloque que de hecho han constituido los regímenes de facto del Cono Sur" ${ }^{\prime 4}$.

El militar argentino Suárez Mason clausuró el evento requiriendo a los pueblos y países de Latinoamérica la unión frente a la amenaza comunista y a los delegados que hiciesen comprender que el peligro mayor se cernía sobre América Central que, de caer en manos del comunismo, constituirá una cuña divisoria del continente amenazado $^{48}$. Asimismo denunció la política exterior del presidente Carter como "instrumento de un proyecto neocolonial marxista" 49 , lo cual legitimaba el accionar de la CAL y de la dictadura argentina en la región. Suárez Mason se comprometió a enviar a Centroamérica asesores argentinos que transmitiesen la experiencia argentina y la Liga Anticomunista Mundial a aportar 8 millones de dólares para los gastos iniciales (Martorell, 1999, p. 204).

Es importante señalar que el IV Congreso de la CAL en Buenos Aires fue listado por la Cancillería argentina como un congreso oficial, lo cual debe haber favorecido el financiamiento y la puesta en disponibilidad de recursos del Estado argentino de todo tipo (Ministerio de RREE y Culto, 1980, p. 107). Ello le da otra connotación a las actividades propuestas para el último día. Los doscientos delegados de la organización transnacional de extrema derecha fueron trasladados a Campo de Mayo, una de las guarniciones militares más grandes

\footnotetext{
46 "El Congreso anticomunista dio su apoyo a los gobiernos del Cono Sur", 4 de septiembre de 1980, Clarin, p. 8.

47 "Denuncian anticomunistas una conspiración marxista contra Latinoamérica dirigida desde Cuba y la URSS", $1^{\circ}$ de septiembre de 1980, Uno Más Uno.

48 "El Congreso anticomunista dio su apoyo a los gobiernos del Cono Sur", 4 de septiembre de 1980, Clarín, p. 8 y "Suárez Mason instó a la unión ante el comunismo", 4 de septiembre de 1980, La Nación, p. 1.

49 "Congreso anticomunista", 4 de septiembre de 1980, La Nación, p. 6.
} 
del país donde, según la prensa, rindieron homenaje a las víctimas del terrorismo y visitaron el Museo de la Subversión ${ }^{50}$, un sitio siniestro negado por los militares hasta fines de la década del noventa ${ }^{51}$. Como hemos señalado anteriormente, en Campo de Mayo, según Armony y algunos periodistas, oficiales guatemaltecos se formaron en inteligencia y técnicas de interrogatorio. Allí había un CCD, como demostraron el Informe de la CONADEP y varias de las sentencias judiciales por delitos de lesa humanidad. La importancia que revistieron los CCD — O LDT en la jerga militar- en el modus operandi de la represión urbana y la desaparición forzada de personas en Argentina fue tal que la formación en ese tema específico llegó a constituir el objetivo principal de los Cursos de Inteligencia para Oficiales Extranjeros que se impartían en Argentina. La finalidad del curso programado para 1980, al cual asistieron varios guatemaltecos, fue "proporcionar conocimientos técnicos profesionales, especialmente relacionados con la $\mathrm{LDT}$ " 52 .

Desde entonces, según explica Martorell, los agentes argentinos llegaron en grandes cantidades a Honduras, Guatemala, El Salvador o Costa Rica:

Muchos de ellos lo hicieron detentando cargos diplomáticos y gozando de la inmunidad respectiva. Allí, rápidamente, se convirtieron en consejeros secretos en contrainsurgencia para los grupos de ultraderecha y los regímenes totalitarios. En Guatemala trabajaron estrechamente ligados a Mario Sandoval, el que, bajo su manto, había congregado a represores de El Salvador y Nicaragua (Martorell, 1999, p. 205).

Si bien no podemos documentar esta última afirmación de Martorell con un operativo específico, las condiciones de posibilidad para que esto sucediera estuvieron dadas. Como se ha mostrado, Sandoval

\footnotetext{
50 "Finaliza hoy el congreso anticomunista", 3 de septiembre de 1980, La Nación, p. 10.

51 "La represión no se acabó con la democracia", 15 de marzo de 1999, Página 12. Disponible en https://www.pagina12.com.ar/1999/99-03/99-03-15/pag08.htm.

52 Ejército Argentino, Boletin Reservado, № 4844, Anexo: Plan de cursos complementarios, Año 1980, p. 31.
} 
Alarcón y su familia contaban con contactos políticos y personales en Argentina. Él solía acercarse a la Embajada y trabajaba con los militares de Guatemala. Podemos mencionar también el caso de otras mediaciones argentinas de la CAL. El periodista Juan José Salinas afirma que en el IV Congreso participó el argentino Mario Alfredo Mingolla, a quien reconoce en las fotos que muestran los periódicos $^{53}$. El mismo había llegado a Bolivia en 1977 como militante de la WACL y después del narcogolpe del general García Meza, como agente de inteligencia del Ejército argentino que reportaba al Departamento Séptimo de Operaciones Psicológicas boliviano ${ }^{54}$. El mismo Mario Mingolla está citado en una de las fichas del Archivo Histórico de la Policía Nacional de Guatemala: Mingolla se ofreció de enlace entre el 'Departamento 7 'OPSIC' Estado Mayor General del Ejército Rep. de Bolivia[, cuya sección] cuenta con modernos métodos para combatir la subversión", y la dependencia de la Policía de Guatemala ${ }^{55}$. Esta ficha es importantísima, pues el envío de asesores argentinos al Estado Mayor General del Ejército de Bolivia, en comisión permanente, fue sorprendente e ilustra otros espacios posibles de transferencia de recursos de Argentina hacia Guatemala a través de miembros de la $\mathrm{CAL}^{56}$.

\footnotetext{
53 Salinas, Juan José, "El represor más estrafalario: Breve historia de Mario Alfredo Mingolla Montrezza que pasó de ser el batata 'Christian' al obispo Valerian de Silio”, Pájaro Rojo (9 de abril de 2014). Recuperado de 2016 de http:/ / pajarorojo.com.ar/?p=806.

54 El 17 de julio de 1980, militares bolivianos ligados al narcotráfico, en connivencia con la dictadura militar argentina, realizaron el golpe de Estado en Bolivia que evitó la asunción a la Presidencia de Siles Suazo e inició un nuevo período de dictadura institucional de las Fuerzas Armadas bajo el liderazgo de Luis García Meza. Muchos cables de la Cancillería argentina documentaron la intervención Argentina en el golpe en Bolivia. Martín Sivak entrevistó a Mingolla en 2001 (Sivak, 2001, p. 241).

55 Ficha Mingolla, Alfredo Mario, No 86, carpeta Direcc. Generales, 26 de julio de 1982, Departamento de Investigaciones Técnicas, Policía Nacional, AHPN, Doc 1058834. Recuperado de https://ahpn.lib.utexas.edu/es/search/documento/1058834?s=Mingolla\#page/1/mode/1up Por esta ficha suponemos que Mingolla estaba en Guatemala. Algunos periodistas señalan que desde 1979 había sido enviado a Honduras como parte del Grupo de Tareas Exterior. Véase Salinas, Juan José, "El represor más estrafalario: Breve historia de Mario Alfredo Mingolla Montrezza que pasó de ser el batata ‘Christian' al obispo Valerian de Silio”, Pájaro Rojo (9 de abril de 2014). Recuperado de http://pajarorojo.com.ar/?p=806

56 Los asesores a Bolivia iban en comisión entre 395 y 761 días, un dato que destaca en relación a las comisiones a otros países de la región. Véase, por ejemplo, el Boletín Reservado
} 
Nuestras investigaciones dan cuenta de que fluyó hacia Centroamérica una buena cantidad de asesores argentinos expertos en inteligencia, sobre todo hacia Honduras. Un cable recientemente desclasificado, procedente de la Embajada argentina en Honduras, ratifica que dos jefes militares argentinos asesoraron en la Escuela de Comando y Estado Mayor hondureña y cambiaron los "procedimientos" de origen norteamericano por otros más similares a los utilizados en Argentina. Dichos asesores, cita el cable, fueron Gigante y de la Vega ${ }^{57}$. En efecto, el Ejército de Honduras había solicitado la designación de dos oficiales superiores y un oficial jefe para desempeñar funciones que, según el decreto, no podían ser "cumplidas por miembro alguno de la representación diplomática o misión militar existentes en el mencionado país, dado el carácter especial de las mismas". Así, el presidente argentino decretó designar en comisión permanente a los coroneles Carmelo Roberto Gigante y José Osvaldo Riveiro y al teniente coronel Abelardo Carlos de la Vega para desempeñar "las funciones de asesores en Institutos de Perfeccionamiento del Ejército de la República de Honduras" ${ }^{58}$. Gigante había sido instructor en la Escuela de las Américas, subdirector de la Escuela Superior de Guerra de Argentina y fue designado como asesor en inteligencia. Riveiro fue agente del Batallón de Inteligencia 601 del Ejército y trabajaba en la jefatura de inteligencia. De la Vega fue profesor de inteligencia en la Escuela Superior de Guerra y fue designado como asesor auxiliar de acción psicológica. Desde Honduras, estos militares y un buen número de los oficiales destinados a América Central "cumplieron funciones trascendentes ordenadas por el Ejército [para toda el área, una] actividad de Inteligencia Estratégica que no es conocida

del Ejército Argentino, No 4650, 13 de febrero de 1976. Anexo: Programa de Actividades y movimiento anual de personal en misión en el exterior. Año 1977, pp. 18-20 o el Boletín Reservado, $N^{\circ}$ 4877, 6 de junio de 1980.

57 El cable dice: "modificaron [el] programa original de origen norteamericano según [el] modelo [de la] escuela [de] EE. UU. en Panamá, y establecieron [un] plan de estudios y ejercicios sobre [la] base [de] necesidades propias, buscando formar doctrina nacional genuina de defensa, con procedimientos similares a utilizados en nuestro país". Cable cifrado, de Ossorio Arana, Honduras, 18 de agosto de 1982, MrEC, cForti, Honduras, cr296.

58 Decreto S 43/1981 del 29 de diciembre de 1981, Decretos secretos y reservados, Suplemento, Primera Sección, en Boletín Oficial de la República Argentina, Año CXXIII, Nº 33.077, Buenos Aires, 25 de febrero de 2015, p. 63. 
por la masa de los generales del Ejército puesto que es una actividad secreta" ${ }^{99}$. Es interesante observar que el general guatemalteco Óscar Rodolfo Cuyún Medina, comandante de la brigada de la zona militar correspondiente a la capital de Guatemala, había viajado a Argentina, había recibido una condecoración y fue posteriormente el embajador de Guatemala en Honduras, posiblemente otro enlace ${ }^{60}$. Es altamente probable que dicha actividad de inteligencia estratégica ideada para la región centroamericana haya surgido, o al menos haya sido mentada, en aquella IV Conferencia de la CAL, pues todos estos militares dependieron del jefe del Estado Mayor del Ejército, quien fue presidente de la CAL. Los datos vistos en conjunto y de forma integral constituyen evidencia circunstancial para seguir trabajando en las líneas de nuestra hipótesis de trabajo.

\section{Conclusiones}

La forma de la represión política en las zonas urbanas de Argentina y Guatemala presenta varias similitudes, para cuya explicación arriesgamos una hipótesis sobre la cual trabajamos aquí y seguiremos investigando: la colaboración argentina en los órganos vertebrales que producen la desaparición forzada, como la inteligencia civil y militar. Creemos que la transferencia de recursos, humanos y materiales, de Argentina hacia Guatemala se realizó no solamente a través de canales oficiales, formales y militares, sino también a través de las conexiones civiles y militares, secretas, informales y clandestinas, como fue la red transnacional de extrema derecha denominada Confederación Anticomunista Latinoamericana (CAL). Es una hipótesis muy difícil de comprobar a través del análisis documental por falta de archivos

\footnotetext{
59 Junta Superior de Calificación de Oficiales, 1985, p. 76, Archivo General del Ejército, Argentina. Citado por el Informe Centroamérica que el Equipo de Relevamiento y Análisis de Documentos del Ejército, Ministerio de Defensa, realizó a mi solicitud en 2016.

60 Nota ordinaria, de Óscar Rodolfo Cuyún Medina, embajador de Guatemala en Honduras, al teniente coronel de Policía Mario Ramírez Ruiz, director de la Escuela de Capacitación de la Policía Nacional, 20 de noviembre 1984, nota No 1294/84, AHPN, Doc 1944016. Recuperado de https://ahpn.lib.utexas.edu/es/search/documento/1944016?s=1944016\# page/583/mode/1up
} 
y por los juicios abiertos; se empiezan entonces a reconstruir algunos lazos sociales, políticos, colectivos que aquí procuramos visibilizar como parte de las condiciones de posibilidad para la transferencia de recursos de Argentina hacia Guatemala.

En este trabajo, en efecto, elegimos comprobar la participación de la extrema derecha guatemalteca nucleada en el MLN y el CACIF en la red latinoamericana de la CAL y demostrar sus conexiones con los gobiernos argentinos a través de la variable temporal. Es decir, abordar el qué y el cómo a través del cuándo. En tal sentido, observamos que el periodo de 1975 a 1980 fue central. En el primer año, las relaciones fueron entre gobiernos que contaron entre sus funcionarios principales a los líderes de las organizaciones paraestatales, paramilitares y parapoliciales anticomunistas y en los que las desapariciones forzadas fueron perpetradas por dichas organizaciones. En el segundo año, las relaciones fueron entre gobiernos que comenzaron a institucionalizar la violencia y el modus operandi de las desapariciones forzadas. Guatemala recién estaba profesionalizando la inteligencia, un elemento visceral para las desapariciones forzadas perpetradas entre 1983 y 1985, pero Argentina ya contaba con una exitosa — según la institución castrense- experiencia. La CAL fue un vehículo informal para las relaciones entre civiles y militares de Guatemala y Argentina, pues todos trabajaban conjuntamente en la lucha contra la subversión.

En el artículo hemos procurado mostrar las relaciones que la CAL mantenía con los gobiernos nacionales del subcontinente. Los gobiernos llamados anticomunistas sabían de la existencia de la organización, la apoyaban e incluso la financiaban; funcionarios de alto rango de las dictaduras del Cono Sur presenciaban las inauguraciones de los congresos, pronunciaban discursos en los mismos y también los presidían. En los documentos estudiados hemos encontrado referencias que nos hablan de cierta articulación de la red con los servicios de inteligencia de Paraguay, Brasil, Uruguay, El Salvador y Argentina, por ejemplo. En el IV Congreso de la CAL es muy posible que se hayan vehiculado recursos de Argentina hacia Guatemala, los cuales ya se estaban transfiriendo por canales oficiales. 
Como hemos demostrado ampliamente en otras investigaciones y en esta misma, el IV Congreso no se produjo en un vacío historiográfico, sino en un entramado de relaciones personales y entre organizaciones a través de la CAL y de relaciones diplomáticas que habían cobrado un singular vigor en 1980. Entre 1979 y 1980 hemos documentado, en otro artículo, una serie de acontecimientos en materia de relaciones exteriores entre Argentina y Guatemala que permiten encuadrar la cooperación en seguridad nacional como la creación, en 1980, del Departamento América Central y Caribe en el Ministerio de Relaciones Exteriores de Argentina y la creación de la agregaduría militar en Guatemala. Se produjeron numerosos viajes de delegaciones militares (públicos y secretos), negociaciones de convenios, ofrecimiento de armas, becas y formación en inteligencia, condecoraciones, circulación de libros, etc. (Rostica, 2016).

Los recursos concretos que fluyeron a través de la CAL y a través de las relaciones entre el líder del MLN y los gobiernos de Argentina pueden haber sido de todo tipo. En principio, a través de los congresos, circularon ideas, informaciones, inteligencia y contrainteligencia, pues se consideraba que Argentina había tenido una experiencia exitosa en la lucha contra la subversión. Esto puede considerarse una colaboración argentina a la lucha contrasubversiva en Guatemala, otro elemento más que ayuda a comprender las similitudes en la represión urbana de Argentina y Guatemala y el lugar estratégico de la sección de inteligencia.

\section{Referencias}

Ansaldi, W., \& Giordano, V. (2012). América Latina. La construcción del orden, Buenos Aires: Ariel.

Ansaldi, W., \& Giordano, V. (Coords.). (2014). América Latina. Tiempos de violencias, Buenos Aires: Ariel.

Armony, A. (1999). La Argentina, los Estados Unidos, y la cruzada anticomunista en América Central (1977-1984). Buenos Aires: Universidad Nacional de Quilmes. 
Barón, A. (24 de marzo de 2006). Entrevista exclusiva con el exjefe de la CIA Duane Clarridge.

Calloni, S. (2001). Operación Cóndor. Pacto criminal. México: Ediciones La Jornada.

Calveiro, P. (2006). Podery desaparición. Los campos de concentración en Argentina. Buenos Aires: Colihue.

Cardoso, Ó. R., Kirschbaum, R., \& van Der Kooy, E. (1983). Malvinas. La trama secreta. Buenos Aires: Sudamericana.

Caso Bámaca Velásquez. vs. Guatemala, 25 de noviembre de 2000. Recuperado de http://www.corteidh.or.cr/docs/casos/articulos/Seriec_70_esp.pdf

Caso García y familiares vs. Guatemala, 29 de noviembre de 2012. Recuperado de http://www.corteidh.or.cr/docs/casos/articulos/seriec_258_esp.pdf.

Caso Gudiel Álvarezy otros ("Diario Militar") vs. Guatemala, 20 de noviembre de 2012. Recuperado de http://www.corteidh.or.cr/tablas/fichas/ diariomilitar.pdf

Causa No 17/2012/TO1, caratulada "Vañek, Antonio y otros s/ infrac-

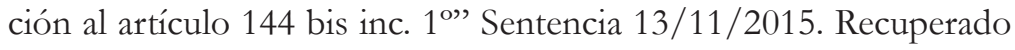
de http://www.crimenesdeestado.untref.edu.ar/ficha-sentencia. php?s $=211 \&$ lang $=$ es

Causa No 1914 "F"-07-TOCFSL, caratulados: "F. s/ Av. Delito (Fiochetti, Graciela)" y sus acumulados Expte. 771-F-06 "Fiscal s/ Av. Inf. Art. 142 bis del Código Penal" (Pedro Valentín Ledesma); Expte. 864-F-06 "Fiscal s/ Av. Infr. Art. 142 bis del Código Penal" (Santana Alcaraz) y Expte. 859-F-06 “Fernández, Víctor Carlos denuncia apremios ilegales"- TOF San Luis- Sentencia 12/03/2009. Recuperado de http:/ /www. crimenesdeestado.untref.edu.ar/ficha-sentencia.php?s=109\&lang=es Causa No 1960/10 "Harguindeguy, Albano Eduardo y otros s/inf. Art. 151 y otros del c. Penal" y sus acumuladas la N 1.991/10 caratulada: "Diaz Bessone, Ramón Genaro y otros s/ inf. Art. 141 y otros del c. Penal", y N²138/11 caratulada: "Valentino, Juan miguel y otros s/ inf. Art. 141 y otros del c. Penal”. TOF- Paraná. Sentencia 27/12/2012. Recuperado de http://www.crimenesdeestado.untref.edu.ar/fichasentencia.php?s=81\&lang $=\mathrm{es}$

Cisneros, A., \& Escudé, C. (2000). Historia general de las relaciones exteriores de la República Argentina, tomo XIV. Buenos Aires: Grupo Editor Latinoamericano. 
Comisión Interamericana de Derechos Humanos. (11 de abril de 1980). Informe sobre la situación de los derechos bumanos en Argentina. Recuperado de http://www.cidh.org/countryrep/Argentina80sp/indice.htm

Comisión Interamericana de Derechos Humanos. (13 de octubre de 1981). Informe sobre la situación de los derechos humanos en la República de Guatemala. Recuperado de http://www.cidh.org/countryrep/Guatemala81sp/ indice.htm

Comisión Interamericana de Derechos Humanos. (3 de octubre de 1983). Informe sobre la situación de los derechos humanos en la República de Guatemala. Recuperado de http://www.cidh.org/countryrep/Guatemala83sp/ indice.htm.

Comisión Interamericana de Derechos Humanos. (3 de octubre de 1985). Tercer informe sobre la situación de los derechos humanos en la República de Guatemala. Recuperado de http://www.cidh.org/countryrep/Guatemala85sp/indice.htm

Comisión Nacional sobre la Desaparición de Personas (CONADEP). (1984). Nunca más. Buenos Aires: Eudeba.

Comisión para el Esclarecimiento Histórico (CEH). (1999). Guatemala, memoria del silencio, Guatemala: UNOPS.

Cullather, N. (2002). PBSUCCES. La operación encubierta de la CIA en Guatemala, 1952-1954. Guatemala: Asociación para el Avance de las Ciencias Sociales en Guatemala.

Dabat, A., \& Lorenzano, L. (1984). The Malvinas and the end of military rule. londres: Verso.

Demyk, M. (1994). Guatemala, En Rouquié, A. (Coord.). Las fuerzas politicas en América Central. México: Fondo de Cultura Económica.

De Riz, L. (1981). Retorno o derrumbe. El último gobierno peronista. Buenos Aires: Hyspamerica Ediciones.

Doyle, K., \& Kornbluh, P. (s.f.). CLA and ASS ASSINATIONS: The Guatemala 1954 documents. Electronic Briefing Books, 4. Washington, D.C.: National Security Archive. Recuperado de http://www2.gwu.edu/ nsarchiv/ NSAEBB/NSAEBB4/index.html

Ejército Argentino (1977). Operaciones contra elementos subversivos. Buenos Aires: Instituto Geográfico Militar.

Ejército de Guatemala (s.f.). Manual de guerra contrasubversiva elaborado por la Escuela de Comando y Estado Mayor del CEM para fines de instrucción [TE06-1]. Guatemala: Centro de Estudios Militares. 
Feinmann, J. P. (1987). López Rega. La cara oculta de Perón. Buenos Aires: Editorial Legasa.

Figueroa Ibarra, C. (1999). Los que siempre estarán en ninguna parte LLa desaparición forzada en Guatemala]. México: Universidad de Puebla.

Fortuny, J. M. (1977). Observaciones al trabajo de Edelberto Torres-Rivas, Historia y Sociedad, 15, 55-69.

Gasparini, J. (2011). López Rega. La fuga del brujo. Buenos Aires: Norma.

Gleijeses, P. (2008). La esperanza rota. La revolución guatemalteca y los Estados Unidos, 1944-1954. Guatemala: Editorial Universitaria.

Godoy, E. (30 de enero de 2008). Guatemala cooperó en planes Cóndor y Calipso. Presna Libre.

González Janzen, I. (1986). La Triple A. Buenos Aires: Editorial Contrapunto. González Ruiz, É. (2006). Cruces y sombras. Perfiles del conservadurismo en América Latina. San José de Costa Rica: Asociación Colectiva por el Derecho a Decidir.

Gordillo Castillo, E. (2004). Dios, patria y libertad: una historia del Movimiento de Liberación Nacional - MLN- (1960-2000). Política y Sociedad, 42, 87-102.

Gramajo Morales, H. A. (1995). De la guerra ... a la guerra. Guatemala: Fondo de Cultura Editorial.

Grandin, G. (2001). Denegado en su totalidad. Documentos estadounidenses liberados, Autores Invitados, 5, AVANCSO.

Guerrero, A. (7 de marzo de 2005). El narcotráfico es consecuencia de la financiación de la guerra en Centroamérica. Radio Nizkor.

Izaguirre, I. (2009). Lucha de clases, guerra civily genocidio en la Argentina 19731983. Buenos Aires: Eudeba.

Larraquy, M. (2007). López Rega, el peronismo y la Triple A. Buenos Aires: Punto de Lectura.

López Macedonio, M. N. (2010). Historia de una colaboración anticomunista transnacional. Los tecos de la Universidad Autónoma de Guadalajara y el gobierno de Chiang Kai-Shek a principios de los años setenta. Contemporánea (1), año 1, 133-158.

López, F. (2016). The feathers of condor: Transnational state terrorism, exiles and civilian anticommunism in South America. United Kingdom: Cambridge Scholars Publishing.

Marín, J. C. (1996). Los hechos armados. Argentina 1973-1976. La acumulación primitiva del genocidio. Buenos Aires: La Rosa Blindada y PICASO. 
Martorell, F. (1999). Operación Cóndor. Santiago de Chile: LOM Ediciones.

McSherry, J. P. (2009). Los Estados depredadores: la Operación Cóndor y la guerra encubierta en América Latina. Santiago de Chile: LOM Ediciones.

McSherry, J. P. (2012). La maquinaria de la muerte: la Operación Cóndor. Revista Taller (1), 1, 33-45.

Ministerio de Relaciones Exteriores y Culto. (1980). Memorias de 1980. Buenos Aires: MREC.

Paino, S. H. (1984). Historia de la Triple A. Montevideo: Editorial Platense S.A.

Pinto Recinos, R. A. (2004). La muerte del coronel Francisco Javier Arana y la rebelión de la Guardia de Honor de 1949. Política y Sociedad, 42, 28-44.

Programa Verdad y Justicia. (2015). El Batallón de Inteligencia 601. Buenos Aires: Dirección Nacional del Sistema Argentino de Información Jurídica, Ministerio de Justicia y Derechos Humanos.

Ramírez Fuentes, J. A. (2016). Aglutinando a las derechas: los primeros años del partido Arena, 1979-1984. En R. García Ferreira \& A. Taracena Arriola (Eds.), La Guerra Fría y el anticomunismo en Centroamérica (pp. 269-290). Guatemala: FLACSO-Guatemala.

Rostica, J. C. (2011). Apuntes sobre la Triple A. Argentina 1973-1976. Revista Desafíos, 23 II, 21-51.

Rostica, J. C. (2015). Las dictaduras militares en Guatemala (1982-1985) y Argentina (1976-1983) en la lucha contra la subversión. Latinoamérica, 60, 13-52.

Rostica, J. C. (2014). Las legitimaciones de la dictadura militar de Guatemala. 1982-1985. Revista Aletheia (4)8.

Rostica, J. C. (2016). La política exterior de la dictadura cívico-militar argentina hacia Guatemala (1976-1983). Revista Estudios, 36, 95-119.

Russell, R., \& Tokatlian, J. (1986). Argentina y la crisis centroamericana, 19761985. Buenos Aires: Flacso.

Santero, D. (24 de marzo de 2006). Las instrucciones: guerra sucia de exportación. Clarín. Recuperado de http:/ / edant.clarin.com/suplementos/ especiales/2006/03/24

Seoane, M. (24 de marzo de 2006). Las operaciones clandestinas en Latinoamérica: Bolivia, Nicaragua, Honduras, Guatemala, El Salvador. Clarín.

Sigal, S., \& Verón, E. (1988). Perón o muerte. Buenos Aires: Hyspamerica Ediciones.

Sivak, M. (2001). El dictador elegido. Biografía no autorizada de Hugo Banzer. La Paz: Plural Editores. 
Slatman, M. (2012). Archivos de la represión y ciclos de producción de conocimiento social sobre la coordinación represiva. Revista Taller (1) 1, 47-66. Stepan, A. (1988). Repensando a los militares en política. Cono Sur: un análisis comparado. Buenos Aires: Sudamericana/Planeta.

Taracena Arriola, A. (1989). El primer Partido Comunista de Guatemala (1922-1932). Diez años de una historia olvidada. Anuario de Estudios Centroamericanos (15) 1, 49-63.

Taracena Arriola, A. (2007). Historia, memoria, olvido, conflicto armado y violaciones de los derechos humanos. Los avatares de la Comisión de Esclarecimiento Histórico de Guatemala. En Stabili, M. R. (Coord.). Entre historias y memorias: los desafios metodológicos del legado reciente de América Latina. (pp. 91-112). Madrid: Iberoamericana.

Villagrán Kramer, F. (1993). Biografía politica de Guatemala. Los pactos políticos de 1944-1970. Guatemala-Costa Rica: Flacso.

Villagrán Kramer, F. (2004). Biografía política de Guatemala. Años de guerra y años de paz: Guatemala: Flacso.

Visconti, S., \& Rodríguez Díaz, U. (2012). Antecedentes de la Operación Cóndor: La Conferencia de Ejércitos Americanos (Montevideo, 1974) y la coordinación de los servicios de inteligencia y los aparatos represivos del Cono Sur. Revista Taller (1)1, 139-150. 